\title{
FILOSOFIA: ENTRE O ENSINO E A PESQUISA - ENSAIOS DE FORMAÇÃO 10 ANOS DEPOIS: OFICINA DE LEITURA E PRODUÇÃO DE TEXTOS FILOSÓFICOS
}

\author{
Adriana Delbó Lopes ${ }^{1}$ \\ Eduardo Ferraz Franco ${ }^{2}$
}

\begin{abstract}
Resumo:
O presente artigo retoma a proposta de oficina de leitura e produção de textos filosóficos relatada no livro Filosofia: entre o ensino e a pesquisa - ensaios de formação (org. Carmelita B. de Freitas Felício), dez anos após sua escrita e, numa atividade dialógica entre discípulo e mestra, demonstra na prática a fertilidade da proposta que, ao explorar a diversidade de gêneros e estilos literários em filosofia, suscita pensamentos distintos, valorizados por cada modalidade de expressão específica. Realçar a importância da diversidade de modos de se expressar pensamentos, como fator enriquecedor artístico e estilístico da criação filosófica, é o propósito deste trabalho. Tal realce tem consequências importantes na relação pedagógica entre discípulo e mestre no ensino da filosofia. Dentre as reflexões explanadas nas experiências de escrita compiladas, a reivindicação da espacialidade como conceito relevante em filosofia, para promover a descolonialidade do sujeito de pensamento, permeia todo o escrito. Tal reivindicação tem relação com práticas transdisciplinares e transculturais.
\end{abstract}

Palavras-chave: Gêneros literários. Correspondência. Aforismo. Ensaio. Descolonialidade.

\section{PHILOSOPHY: BETWEEN TEACHING AND RESEARCH - FORMATION ESSAYS 10 YEARS LATER: READING AND PRODUCTION WORKSHOP OF PHILOSOPHICAL TEXTS}

\begin{abstract}
:
This article takes up the proposal for a workshop on reading and production of philosophical texts reported in the book Philosophy: between teaching and research - formation essays (org. Carmelita B. de Freitas Felício), ten years after its writing and, in an activity dialogical between disciple and master, it demonstrates in practice the fertility of the proposal that, when exploring the diversity of genres and literary styles in philosophy, raises different thoughts, valued by each type of specific expression. To emphasize the importance of the diversity of ways of expressing thoughts, as an artistic and stylistic enriching factor of philosophical creation, is the purpose of this work. Such highlighting has important consequences on the pedagogical relationship between disciple and master in the teaching of philosophy. Among the reflections explained in the compiled writing experiences, the claim of spatiality as a relevant concept in philosophy, to promote the decoloniality of the subject of thought, permeates all writing. Such a claim is related to transdisciplinary and transcultural practices.
\end{abstract}

Keywords: Literary genres. Correspondence. Aphorism. Essay. Decoloniality.

\section{Introdução}

O livro Filosofia: entre o ensino e a pesquisa - Ensaios de Formação, organizado pela Prof. a Carmelita Brito de Freitas Felício, foi publicado no ano de 2012. Este livro compila ensaios escritos por professores universitários, professores do ensino médio e então graduandos

\footnotetext{
1 Graduação em Filosofia (Pontifícia Universidade Católica de Campinas-1997), mestrado em Filosofia (Pontifícia Universidade Católica de Campinas-2000), doutorado em Filosofia (Universidade Estadual de Campinas-2006), Pós-doutoramento (Universidade de São Paulo-2008). Atualmente é professora na Universidade Federal de Goiás. E-mail: delbo@ufg.br. http://orcid.org/0000-0002-5841-1932

2 Doutorando em Geografia pela Universidade Federal de Goiás, Regional de Jataí - GO. Mestre em filosofia pela Universidade Federal de Goiás. E-mail: eferrazfranco@ hotmail.com. http://orcid.org/0000-0002-5637$\underline{9342}$
} 
em filosofia da Universidade Federal de Goiás, que fizeram parte do Programa Institucional de Bolsas de Iniciação à Docência, PIBID, entre os anos de 2010 e 2011. Os ensaios são reflexo de um movimento que objetivou tornar o ensino de Filosofia uma questão filosófica naquela instituição.

De um modo geral, o livro apresenta reflexões críticas e filosóficas oriundas da intervenção prática dos bolsistas do PIBID no Colégio estadual Pré-Universitário, em Goiânia. Dentre as experiências que embasam as reflexões, a realização de uma oficina de leitura e produção de textos filosóficos. A realização da oficina teve, de acordo com definição apresentada por um estudante bolsista, o propósito de explorar diferentes estilos literários para a escrita filosófica:

Na contramão da tendência acadêmica de que se tem um estilo literário padrão para a escrita filosófica, que para se escrever filosofia deve-se seguir uma série de normas para que a escrita seja, de fato, uma dissertação filosófica, buscamos explorar diversas expressões do pensamento filosófico (FRANCO, 2012, p. 137).

O recurso à diversidade de estilos literários para o pensamento filosófico foi fundamentado pela afirmação de Marcondes et al. (2011, p. 32) de que "encontramos diferentes estilos de texto filosófico e [...] o uso de cada um deles parece desempenhar um papel fundamental na expressão do pensamento de cada filósofo".

Dez anos após a escrita dos ensaios que compõem o livro, um dos, à época, estudantes bolsistas do PIBID, se reencontrou com a professora que outrora fora sua orientadora, na oficina intitulada Tramas da filosofia: entre o pensamento e a avaliação, realizada em abril de 2021, onde se promoveu a revisita há alguns ensaios do livro em questão, bem como a retomada das discussões sobre a importância da diversidade de gêneros ou estilos literários para a expressão do pensamento filosófico. Como materialização deste diálogo, experiências de escrita em diferentes estilos foram criados, exemplificando a especificidade, as vantagens e desvantagens de alguns gêneros literários, bem como trazendo, de modo inusitado e informal, algumas discussões filosóficas importantes acerca do ensino, aprendizagem e avaliação em Filosofia.

Três estilos literários foram escolhidos para dar voz, de acordo com suas especificidades, às reflexões atinentes à temática da avaliação como potencializadora do pensamento e da aprendizagem, são eles: a correspondência, o aforismo e o ensaio. Retomando definições expostas no livro Filosofia: entre o ensino e a pesquisa - Ensaios de Formação,

\begin{tabular}{|l|l|l|l|l|}
\hline Ronista Dialectus & Ano 10 & n. 23 & Maio - Agosto 2021 & p. $13-32$ \\
\hline
\end{tabular}


destacamos que, segundo Pereira (2012), à esteira de Foucault, as cartas têm a função de treino de si, uma atividade auto formativa, onde, na relação mestre-discípulo, a avaliação de um para com o outro tem papel preponderante. De cordo com Pereira (2012, p. 270), para

\footnotetext{
as correspondências, uma narrativa de si em detalhes é privilegiada; quando se coloca na frente do outro, com uma meticulosa atenção a tudo que se passa no corpo e na alma, o remetente solicita o seu olhar e oferece o olhar que tem de si mesmo, para educá-lo, se for um discípulo, ou para comunicar a um mestre que em suas atividades, a única coisa relevante fora ocupar-se de si mesmo.
}

Quanto aos aforismos, a citação de Deleuze (s/d, p. 50), os definindo como "arte de interpretar", e de Marcondes et al. (2011, p. 40), como o estilo "da força expressiva das palavras" capaz de "surpreender o leitor e levá-lo a pensar", são elucidativos. A respeito do ensaio, a apresentação do livro, feita pela organizadora da obra, Felício (2012, p. 12), explica que "quer dizer 'ato de pensar", que a autora aproxima de um "exercício experimental", que Arendt (apud FELÍCIO, 2012, p.13) caracterizava como "pensamento [que] emerge da concretude dos acontecimentos" e que Felício afirma estar alojado no "espaço entre".

\section{Correspondências}

\subsection{Carta do discípulo para a mestra}

Querida Adriana Delbó,

É uma felicidade imensa poder participar de uma oficina ministrada por você, depois de alguns anos desde que conclui meu ciclo na Faculdade de Filosofia na UFG. Outro grande prazer foi ser mobilizado a retomar o livro Filosofia: entre o ensino e a pesquisaEnsaios de formação. Já se vão quase dez anos desde que foram escritos os artigos que compõem o livro.

Como as coisas se transformaram no decorrer desta década, não é mesmo? As mudanças são notáveis em diversas escalas: o agravamento da massificação cultural, o consumismo e o avanço do conservadorismo, em escala global; a precarização dos serviços públicos, em escala nacional; a aceleração da devastação do Cerrado, em escala regional. E na escala do sujeito, então? Quanta transformação!

Desde que conclui o mestrado, em 2014, atravesso uma crise epistêmica que alterou minha trajetória. Terminei o curso com a sensação de que, quanto mais me tornava versado em culturas eruditas, mais abandonava as heranças de saberes de outras matrizes, adquiridas em

\begin{tabular}{|l|l|l|l|l|}
\hline Ronista Dialectus & Ano 10 & n. 23 & Maio - Agosto 2021 & p. $13-32$ \\
\hline
\end{tabular}


uma criação simples e interiorana, em uma família e comunidade de pessoas com multiplicidade étnica e detentoras de sabedorias e culturas que estão em extinção (epistemicídio ${ }^{3}$ ).

Naquele momento não via a possibilidade de seguir meus estudos em filosofia acadêmica. Ingressar no doutorado em filosofia para pesquisar saberes originários de outras fontes que não a cultura europeia me parecia impossível (hoje vejo que alguns/mas colegas romperam essas barreiras). Tampouco tinha o interesse e fôlego em prosseguir. Imerso que estava na riqueza cultural das periferias das metrópoles, na luta social e nas experiencias cotidianas em busca de um modo de vida menos alienado, busquei espaços onde minhas energias físicas e intelectuais pudessem ser direcionadas, não para alimentar o capitalismo, mas para materializar utopias libertárias. Dentre os clássicos gregos que me inspiravam, estava Diógenes de Sinope. Mas a corrente cínica ainda teria espaço no mundo e na filosofia contemporâneos?

Nesse processo de ruptura epistêmica me envolvi (e me envolvo) profundamente em projetos culturais e autogestionários nas periferias. As dinâmicas contraculturais me conduziram à Buenos Aires, Argentina, onde passei os anos de 2015 e 16, vivendo coletivamente em uma casa ocupada, respirando luta social e trabalhando como cartonero.

Nesse período ouvi rumores de que havia ocorrido um golpe político no Brasil e que as coisas não iam bem. Mesmo sem compreender exatamente o que estava acontecendo, senti a necessidade de regressar. Além da notícia de uma iminente crise política e social sem precedentes no nosso país, estar fora do território em que nasci e que adquiri vínculos de territorialidade ${ }^{4}$, contribuiu para a decisão de retornar para o lugar onde primeiro aprendi viver. O recurso que possuía permitiu que fizesse a viagem em bicicleta (também era um desejo antigo). No trabalho da reciclagem e com a ajuda de amigos, montamos bicicletas e viemos, eu e dois amigos (apenas um completou a viagem comigo), em direção ao Brasil central.

O trajeto da viagem foi emblemático, pois possuía uma unidade geográfica, compunha uma região ${ }^{5}$ representável por uma bacia hidrográfica. Percorremos quase toda a

3 Sobre o conceito de epistemicídio: "Nisso consistiu o epistemicídio, ou seja, a supressão dos conhecimentos locais perpetrada por um conhecimento alienígena. De facto, sob o pretexto da 'missão colonizadora', o projeto da colonização procurou homogeneizar o mundo, obliterando as diferenças culturais" (SANTOS; MENESES, 2013, p. 17).

4 "Territorialidades [...] se desenvolvem em íntima conexão com os ambientes em suas dimensões paisagística (aparência, espaço visível) e diretamente material ou tangível, quer sejam as dinâmicas e os processos naturogênicos dos (geo)ecossistemas, quer sejam as formas e as dinâmicas já nitidamente produzidas socialmente" (SOUZA, 2019. p. 84)

5 Na esteira do pensamento do geógrafo Rogério Haesbaert, propomos aqui a utilização do conceito de Região para além da arbitrariedade do recorte espacial baseado em características físicas homogêneas. O que está em questão é a similitude da imposição da colonialidade em um recorte espacial que transpõe fronteiras de

\begin{tabular}{|c|c|c|c|c|}
\hline Ronista Dialectus & Ano 10 & n. 23 & Maio - Agosto 2021 & p. $13-32$ \\
\hline
\end{tabular}


bacia do rio Paraná (e quase metade da do rio de la Plata). Saímos de Buenos Aires em direção à Rosário, foz do rio Paraná com o de la Plata, percorremos boa parte rio, à montante, pela margem direita, percorrendo as províncias de Santa fé e Chaco. Em Chaco cruzamos o rio para a outra margem, na cidade de Resistencia. Do outro lado do rio fica a província de Corrientes, que percorremos pela margem esquerda do Paraná até chegar à província de Missiones, onde as planícies começam a ganhar altitude, em las sierras de Missiones, em sentido ao planalto central, cumieira do nosso subcontinente.

Margeando o rio Paraná cruzamos a foz do Iguaçu na tríplice fronteira. Em rápida expedição, atravessamos para a margem direita do Paraná, para conhecer a Ciudad del Este, no Paraguai, magnífica terra onde o idioma mais falado é o Guarani. De volta à margem esquerda do rio, no sudoeste do estado do Paraná, seguimos ganhando altitude em direção ao norte daquele estado.

$\mathrm{Na}$ foz do rio Paranapanema cruzamos para o estado de São Paulo, no outro dia atravessamos para a margem direita do rio Paraná e continuamos a acompanhar sua margem atravessando a parte leste do estado do Mato Grosso do Sul. Na junção dos rios Grande e Paranaíba, formadores maiores do Paraná, que é o segundo maior rio em extensão da América do sul, seguimos pela margem direita do Paranaíba, até a foz do rio Aporé, divisa do estado do Mato Grosso do Sul com Goiás. De Cassilândia, município limítrofe, tomamos um ônibus, e cruzamos ainda os rios Corrente e Verde, importantes rios do sudoeste de Goiás e que desaguam no Paranaíba. Descemos em Jataí, cidade situada às margens do córrego homônimo, que desagua no rio Claro, importante afluente do Paranaíba. Depois de um descanso, seguimos, novamente em bicicleta, e cruzamos os rios Turvo, dos Bois e Meia Ponte, todos afluentes do Paranaíba, e fomos em direção à Goiânia.

Relato este trajeto porque o encaro como um marco em minha vida. Uma pesquisa de campo transdisciplinar (quem disse que filósofo não faz trabalho de campo? Talvez aqueles que acreditam que o sujeito do conhecimento é neutro e universal), que me ajudou a fundamentar pensamentos que julgo serem filosóficos, mas que estão, ao mesmo tempo, profundamente relacionados com o espaço, os territórios, a geomorfologia, a geografia, mas também com a história, sociologia, antropologia e arqueologia. Percorrendo essa extensa bacia

territórios nacionais. Portanto, propõe-se "uma releitura da questão regional à luz de problemáticas mais especificamente latino-americanas, e que nos permitem reavaliar o conceito de região e os métodos de regionalização fundamentados nas particularidades e singularidades do nosso contexto geo-histórico. Pensar a partir da especificidade de um olhar e de uma prática latino-americana, sem perder de vista sua intensa articulação dentro do sistema-mundo capitalista, significa, hoje em dia, ultrapassar a colonialidade do saber e do fazer" (HAESBAERT, 2021, p. 258).

\begin{tabular}{|c|c|c|c|c|}
\hline Rovista Alatectus & Ano 10 & n. 23 & Maio - Agosto 2021 & p. $13-32$ \\
\hline
\end{tabular}


hidrográfica, contemplando-a em seus pormenores, pude testemunhar a biodiversidade, bem como as diversidades climáticas e de formações geológicas, ao mesmo tempo em que pude notar o avassalador processo de homogeneização das paisagens, de substituição da biodiversidade natural pela mesmice da monocultura, que promove a extração da riqueza local e a substitui por culturas exógenas, que só sobrevivem através da intervenção química.

A mesma diversidade e o mesmo processo de homogeneização pode ser percebido quanto às culturas humanas (análogo aos insumos que propiciam a cultura de plantas exógenas, o ar condicionado do gabinete dos intelectuais é um dos insumos que propicia artificialmente as condições para a cultura europeia em solos tropicais). Diversidades de modos de ocupação, de gêneros de vida humana, também compõem a biodiversidade. A biodiversidade entre os seres humanos também está ameaçada. Parece-me que há uma monocultura ${ }^{6}$ quanto à humanidade, e esta monocultura é eurocentrada, branca, heterossexual e patriarcal. A ciência moderna e a tecnologia são fomentadas para conservação da monocultura e tenta extirpar, subhierarquizando, as culturas originadas de matrizes diferentes. Por fortuna, a esse processo, há r-existências ${ }^{7}$, e ao mesmo tempo em que se impõem as colonialidades, as culturas eurocentradas, o povo se reinventa e reproduz os resquícios de outras matrizes culturais.

Tantos quanto são as diversidades faunísticas e florísticas e as diferentes formações geomorfológicas, seriam as possibilidades de desenvolvimento agropecuário para manter a vida humana. A preguiça europeia em compreender a diversidade faunística e florística, e em aprender com as comunidades originárias a extrair os recursos necessários para reprodução da vida humana desta biodiversidade, impõe a monocultura. Tantas também são as possibilidades de perspectivas, de pontos de vista, de olhares para interpretação da existência e do mundo, múltiplas são as possibilidades de filosofias a partir de cada um desses pontos de vista. A imposição da colonialidade, da homogeneidade cultural, mata, ou tenta matar, outras possibilidades epistêmicas.

... Foi então que decidi retomar a vida acadêmica ... A escolha por geografia foi um acaso nada casual... Ao mesmo tempo e, por outro lado, as respostas para minhas inquietações filosóficas indicavam que a alternativa à homogeneização cultural eurocêntrica é o vínculo

6 As reflexões aqui expressas têm o objetivo de valorizar a pluralidade de modos de se pensar, na esteira de Boaventura de Sousa Santos, que com sua obra, "confronta a monocultura da ciência moderna com uma ecologia de saberes" (SANTOS, 2013, p. 45)

7 Conceito atribuído ao geógrafo Carlos Walter Porto-Gonçalves: "r-existência, isto é, uma forma de existir, uma determinada matriz de racionalidade que atua nas circunstâncias, inclusive re-atua a partir de um topoi, enfim, de um lugar próprio, tanto geográfico como epistêmico" (PORTO-GONÇALVES apud HAESBAERT, 2021, p. 153-4).

\begin{tabular}{|c|c|c|c|c|}
\hline Rovista Dialectus & Ano 10 & n. 23 & Maio - Agosto 2021 & p. $13-32$ \\
\hline
\end{tabular}


territorial do sujeito que pensa, seu lugar de enunciação ${ }^{8}$, sua localização no mundo, e os processos que o atingem ali, naquele lugar. Os conceitos e categorias da geografia têm me auxiliado muito na compreensão desses problemas, e o espaço ocupado pelo sujeito do pensamento não me parece categoria efêmera na criação filosófica.

Deleuze e Guattari (1992) escreveram sobre a Geofilosofia, sobre cartografia conceitual, sobre territorialização, desterritorialização e reterritorialização do pensamento. Mais que um espaço no mundo conceitual, as ideias e pensamentos ocupam um lugar no mundo concreto (e isto Schopenhauer já ensinava, a interpretação filosófica do mundo só é possível porque o sujeito do pensamento está enraizado no mundo, pode sentir o mundo em $\mathrm{si}^{9}$ ). $\mathrm{O}$ espaço em que se territorializa um sujeito que concebe pensamentos, bem como todas as tensões e contradições em torno do poder de controle daquele espaço, e o seu posicionamento em relação às estruturas de poder; por maior que seja a sua pretensão de universalidade, seu desejo de visualizar o fenômeno de fora, objetivamente; o pensamento emerge de um lugar e é resultado de processos que atingem um ponto no tempo e no espaço. Tais fatores exercem influência sobre o sujeito de pensamento. A episteme, e os seus frutos, recebem interferências ideológicas em seu processo constitutivo.

Quando iniciei a escrita desta carta a minha intenção era a de escrever um artigo, dialogando com o texto que você publicou no livro Filosofia: entre o ensino e a pesquisa. Quis conversar com os pensamentos que você materializou a partir de um ponto no espaço e no tempo, em Goiânia, arredores do Campus Samambaia, há mais ou menos dez anos atrás. Pensamentos que, pelo milagre da escrita, você deixou como colaboração para o desenvolvimento de reflexões em outros pontos espaço-temporais. Talvez a escrita conecte os pontos de distintos instantes espaço-temporais, porém, não de maneira homogênea, pois é provável que o conteúdo tenha repercussões distintas em cada perspectiva.

Decidi escrever uma carta por ser, este gênero de escritura, menos cerceado pelas convenções ${ }^{10}$ acadêmicas, permitindo abordar as ideias de maneira mais informal, os conceitos

8 "O essencial aqui é o locus da enunciação, ou seja, o lugar geopolítico e corpo-político do sujeito que fala. Na filosofia e nas ciências ocidentais, aquele que fala está sempre escondido, oculto, apagado da análise" (GROSFOGUEL, 2013, p. 382)

9 A partilha, do sujeito de conhecimento, nos fenômenos do mundo fornece, segundo este filósofo, a chave para a interpretação: "podemos lançar uma olhada no interior da Natureza, que não é senão nosso próprio interior, na qual a Natureza, chegada ao grau supremo a que sua atividade pôde elevar-se, se encontra iluminada na consciência individual pela luz do conhecimento. [...] O subjetivo nos serve para a interpretação do objetivo (SCHOPENHAUER, 1950, p. 381-2).

10 “Oh, que será de ti, meu pobre João do Deserto, se, como é de esperar, aquilo que trouxeres não estiver redigido segundo a convenção tácita dos senhores da filosofia lucrativa! Eles te verão como alguém que não compreendeu o espírito do jogo e ameaça arruinar todos eles [...]. Mesmo que aquilo que trouxeres fosse a

\begin{tabular}{|l|l|l|l|c|}
\hline Ronista Dialectus & Ano 10 & n. 23 & Maio - Agosto 2021 & p. $13-32$ \\
\hline
\end{tabular}


tornam-se mais maleáveis, o que gera, por sua vez, uma potencialização das hipóteses interpretativas. Além disso, a fronteira entre vida e pensamento fica mais fluida, o pensamento não se separa da experiência do pensar. Seu artigo, Tramas da filosofia: entre o pensamento $e$ a avaliação $o^{11}$, publicado há quase dez anos, em outro momento do seu filosofar, agora me oferecem profundas contribuições para compreender e interpretar o processo que estou narrando nestas linhas, processos ocorridos após a concepção do seu escrito, mas que se tornam mais compreensíveis à luz de ideia ali expostas. A teoria ajuda a compreender experiências confusas, fornece subsídios para uma expressão mais adequada.

Em seu artigo abundam as metáforas do pensamento com o espaço, e isso me parece fundamental! A artística defesa de, ao pensar, se "ensaiar movimentos mais próximos da dança" (DELBÓ, 2012, p. 26), e a definição do que é "próprio à filosofia ser composto de um movimento do pensar que se identificam por meio de problemas" (DELBÓ, 2012, p. 32), me auxiliam a compreender que o/a pensador/a, enquanto sujeito de conhecimento, é um ser no mundo, que absorve do seu entorno as influências e as ferramentas para compor suas reflexões, possui "olhos que olham pra fora não se retirando" (DELBÓ, 2012, p. 39). Quando você caracteriza o filosofar como movimento do pensamento, que se dá pelo repisar de espaços já ocupados, mas também no ocupar de espaços ainda não ocupados, esta ideia pode ser remetida à geofilosofia, ao espaço ocupado pelo conceito em suas dinâmicas. Mas o espaço ocupado pelo conceito não é apenas algo abstrato, do mundo das ideias, o posicionamento de um pensamento em relação a outros conceitos, mas também ao espaço concreto, relativo aos espaços ocupados pelos sujeitos que concebem os pensamentos, influenciados por forças concretas e de identidade que compõem o espaço (território, territorialidade, lugar, paisagem, são conceitos que remetem à distintos modos de se considerar um recorte espacial).

Souza (2019) afirma que o pensamento possui um solo ideológico ${ }^{12}$, mas também é fruto de uma atmosfera biográfica ${ }^{13}$. As filosofias que selecionamos para fundamentar nossos pensamentos (bem como teorias de outros campos do saber) compõem o solo ideológico sobre o qual situa o pensamento, a localização dos conceitos criados no mapa conceitual. Mas o

maior obra-prima do espírito humano, jamais poderia encontrar clemência diante dos olhos deles. Pois não estaria redigido ad normam conventionis" (SCHOPENHAUER, 2001, p. 19).

11 Delbó, 2012.

12 “O 'solo ideológico é aquele substrato sobre o qual 'caminhamos' de maneira razoavelmente consciente, fazendo opções” (SOUZA, 2019, p. 29).

13 'Da 'atmosfera biográfica' recebemos todo tipo de influência, e essas influências nem sempre são consistentes com os valores éticos e políticos que racionalmente adotamos" (SOUZA, 2019, p. 29).

\begin{tabular}{|l|c|c|c|c|}
\hline Ronista Dialectus & Ano 10 & n. 23 & Maio - Agosto 2021 & p. $13-32$ \\
\hline
\end{tabular}


ambiente que formou e forma o sujeito que pensa, assim como as ideologias que influem de maneira inconsciente, transparecem no conteúdo do pensamento.

Se "olhar é uma posição de quem avalia” (DELBÓ, 2012, p. 40), conceber um pensamento também se faz a partir de uma posição. No caso de pensamentos concebidos por sujeitos formados em países colonizados, a tensão entre a imposição da colonialidade do saber (Lander, 2005), os epistemicídos, e as r-existências das contrarracionalidades ${ }^{14}$, fornecem uma atmosfera biográfica peculiar, que deve ser valorizada e não devastada pela monocultura epistêmica. São fontes de criações e de pensamentos que ocupam espaços não pisados pela tradição filosófica.

Se o pensamento, para ser considerado filosófico, precisa estar assentado sobre o solo da tradição filosófica, há que se questionar, como faz W. Mignolo ${ }^{15}$, se filosofia é apenas a interpretação de mundo elaborada a partir dos recursos epistêmicos delegados pela esteira da tradição grega e reivindicada como herança cultural europeia, ou se interpretações e explicações de outras matrizes também podem ser consideradas tradição filosófica (como fez Schopenhauer em relação ao pensamento oriental).

Se o solo da tradição filosófica é somente o legado grego e o que fizeram dele os seus herdeiros europeus (e os que pensaram a partir dessa linhagem específica), há que se combater a suposta superioridade da filosofia frente a outras manifestações humanas, e aprender a ouvir e permitir a incorporação de saberes de outras matrizes, como as africanas, indígenas e mestiças. É importante levar em conta, também, que os primeiros filósofos gregos, como Tales, Pitágoras, Empédocles e outros, foram discípulos da sabedoria egípcia e oriental, e que não erigiram seus pensamentos do nada.

Por melhor que o filósofo aprenda a ver, que adquira "mobilidade para o olhar" (DELBÓ, 2012, p. 40), o faz sempre a partir da posição que ocupa, e esta posição oculta pontos de vista e valoriza outros. Por isso é primordial que o pensador exponha para si e para os outros, em um trabalho de autocrítica, o seu lugar de enunciação. Os privilégios que permitiram atingir aquela formulação, assim como as opressões que impedem que se veja de outra maneira, mas

14 Santos (2014, p. 309) define contrarracionalidades como "outras formas de racionalidade, racionalidades paralelas, divergentes e convergentes ao mesmo tempo".

15 "Pero también podríamos plantearnos qué clase de actividad humana era lo que los griegos denominaron filosofía y que pasó a ser la única forma de pensamiento. ¿Acaso porque los pensadores griegos llamaron filosofía a lo que ellos hacían y la forma de hacerlo, los que se dedican a 'pensar' tienen que pedir permiso a los textos griegos o sus guardianes occidentales en Alemania, Francia o Inglaterra? Podría decirse que los pensadores griegos 'descubrieron' la filosofía. O quizá que solo dieron un nombre a una actividad común a todos los seres humanos" (MIGNOLO, 2007, p. 130).

\begin{tabular}{|c|c|c|c|c|}
\hline Q Rovista Dialectus & Ano 10 & n. 23 & Maio - Agosto 2021 & p. $13-32$ \\
\hline
\end{tabular}


que suscitam uma mirada particular. Junto à questão da localização, é fundamental que o olhar interpretativo explicite as questões de classe, gênero e étnicas envoltas no pensamento, pois a suposta neutralidade e universalidade da ciência moderna (de onde brota boa parte da tradição filosófica), se assentou sobre colonialismos, racismos e patriarcados.

Agradeço imensamente a oportunidade de dialogar com você, Adriana, seja com o seu pensamento elaborado há dez anos, seja com você no presente (espero suscitar continuidade, por meio desta carta). Para mim você foi e é uma pessoa muito qualificada e responsável no ato de avaliar, o que contribui muito com meu processo de movimento do pensamento, por isso me exponho para ser julgado sob o seu olhar, sem medo de que percebas minhas incompletudes, contradições e incoerências, afinal, é com a avaliação do outro que nos detemos sobre o pensamento e melhoramos a sua expressão.

Um abraço afetuoso.

\subsection{Carta da mestra para o discípulo}

Querido Eduardo,

Como tem sido difícil e ao mesmo tempo muito especial escrever uma resposta à sua carta. O que é da ordem dos afetos indizíveis me toma o tempo, o envolvimento, o espanto. Isso é bom tanto quanto trabalhoso, porque faltam palavras, elaborações. Não há o que seja suficiente. A forma faz falta, o formato falta, por causa dos rebuliços que extrapolam. Talvez isso tenha de algum modo a ver com o dionisíaco sem o apolíneo. Parece que diante de tanta imensidão, eu sinto que não consigo ocupar muito bem o espaço.

Você foi para Jataí, seguindo na elevação da vida, está numa construção amorosa de onde nasceu um filho, e se doutorando em Geografia, mas retorna tão filósofo. Que sempre possa ser assim - que as origens não sejam esquecidas e desprezadas. Tratar disso seria inútil e demorado, porque a origem está num lugar sem mapa, sem transporte. A demora desta minha carta não tem a ver com a lentidão numa extensão que eu deveria percorrer, sem conseguir. Tem mais a ver com um tempo necessário para fazer as pazes com a ideia de que nem todo espaço será bem ocupado. Escreverei então a partir da falta - da aceitação de que não responderei a tudo que gostaria.

"Coincidência" incrível o rio Paraná e Corrientes (Ar) entre o seu trajeto de volta ao Brasil e uma estada que fiz por lá em 2015. Fui para uma atividade de trabalho. Como ela durou alguns dias, e se deu em Corrientes e na Universidade Nacional de Salta, no mesmo

\begin{tabular}{|l|l|l|l|l|}
\hline Q & Ano 10 & n. 23 & Maio - Agosto 2021 & p. 13 - 32 \\
\hline
\end{tabular}


período fui à Salta e visitei muito rapidamente o povoado de Cachi. Mas é uma cena no rio Paraná que quero mencionar. Sentada diante deste rio, tive vontade de entrar nele, para brincar, tomar um banho. Mas eu estava na companhia de filósofos que imediatamente me apresentaram os limites: "aqui as pessoas não entram, não nadam". "Deve ser perigoso". "Não é costume". Segui lá, contemplando e ficando imersa em sensações que nem tento explicar, mas então eu já estava sozinha, porque é assim que eu me sinto na companhia de quem apenas põe limites. Eu sei o quanto a organização, o planejamento, as normas são relevantes. Se eu não moro mais numa casa de madeira que tanto envelheceu, cujo telhado estragado abriu tantas goteiras que levavam pra dentro de casa a chuva que precisava molhar só lá fora, isso se deve também ao quanto meus pais planejaram outra vida pra mim e o quanto eu segui este planejamento. Não mencionarei as dificuldades. Minha vida toda tem a ver com isso - com saídas, que se não tivessem se dado... Apesar do quanto isso significa, sair do que é necessariamente planejado também é salutar para que eu tenha ar e consiga movimentos que não se dão em linhas retas. E não tomei banho no rio Paraná, não me molhei nas águas comuns a nós e às nossas irmãs e irmãos originários, destas terras não muito nossas - porque para nós, brasileiras, brasileiros, o que é nosso e do outro nunca se manteve. Nós nos fizemos assim, né? Ou melhor, fomos feitos. Mas foi a sobrevivência o que nos restou sempre depois das graves perdas. Sobreviver é tão importante. Mas viver é tanto quanto. E se apenas o que passou a ser do outro ganhou papel, o que é nosso precisaria ser assim reocupado, recuperado, sem avisos, sem pedidos de autorização, tal como o percurso de um rio, um trajeto imenso de bicicleta, uma volta que se deu por ter sido assim, e uma entrada no rio que eu não fiz, porque deveria ter feito sem avisar. Quantas coisas não são por serem fora do esquadrinhado? E isso não se deve ao gosto pelas aventuras. Não falo agora sobre a vontade do diferente, do proibido. Tento falar sobre o momento crucial que se sai da reta, escapa do que era pra ser, ou não conta com o ideal para resultar em ser. Acredito que este mapa da sua viagem e o seu modo de ocupar os espaços e de estar nos lugares diga muito de você, Eduardo. Não é um aspecto, um detalhe, um lado do Eduardo. Mas a respeito do todo não sabemos, e assim precisa ser.

Mas este Eduardo que tanto aparece no que vejo da sua existência explica a minha necessidade da companhia das estudantes e dos estudantes. Há algo meu que está neste lugar. Lutar eu só consigo assim, sendo acompanhada e acompanhando esta força. Sem contar que foi pela minha condição de estudante que eu consegui ingressar em saídas. Eu gosto imensamente da minha profissão, também porque nela eu sigo na companhia de estudantes, e porque ser professora não é só profissão, embora precise ser também, porque também o trabalho pode

\begin{tabular}{|l|l|l|l|l|}
\hline Q & Ano 10 & n. 23 & Maio - Agosto 2021 & p. 13 - 32 \\
\hline
\end{tabular}


favorecer a construção, os apaziguamentos e mais movimentos. Mas a profissão, o trabalho, as atividades para nos manter, precisam da vida, para que não nos retire a sensação mais verdadeira de estarmos vivas e vivos. O fato de todas e todos nós irmos ocupando outros lugares, outras regiões da nossa vida em sociedade, não significa nos retirar das regiões e de condições anteriores. Mas por causa deste lugar para os estudos, eu percebo minha ligação com quem tem envolvimento com um agora que não passa, um "ainda não", "ainda não sou o que dizem que eu deveria ser". Preciso dos lugares onde eu enxergo as feituras, as tentativas, os ensaios, a tomada de posse do que é cultural, humano, nosso. Em quais outros lugares tomamos posse disso? Nos lugares onde somos capturados pelas criações, ficamos apenas para conseguir sair.

Eu lembro-me que na sua formatura, eu quis conhecer sua mãe e seu pai e dar os parabéns também pra eles, porque, por mais que nossos pais não sejam os únicos responsáveis pelo que somos, eles são um lugar imenso e muito importante para o nascimento, o crescimento, a morada, o mais básico sem o qual não teríamos sequer como nos movimentar para fora da nossa casa originária. Agora você é pai e eu torço para que seu filho sinta amorosamente esta importância que você e sua parceira sempre terão para a vida dele.

É bem arriscado eu conversar com um estudioso da geografia a partir destes termos: lugares, espaços, ocupações, percursos, saídas, retornos, precisar ficar e se adentrar ainda mais (rio Paraná, por exemplo). Mas neste momento eu precisei disso tudo, por causa deste retorno seu pra esta atividade que já fizemos tão bem juntos - estudar, compartilhar estudos. Quando eu estou com quem gosta de aprender, desaprender e de se fazer, eu me sinto bem acompanhada e fortalecida para viver. Antes de perceber isso, eu aceitava não viver. Ficava na sobrevida, na manutenção e até mesmo falta de condições até para isso. Mas sentir onde está o elo, em quais lugares se dão o vínculo, significa encontrar uma fonte límpida. Não se trata mais de ensinar ou precisar aprender a regra do lugar, de ser fora e precisar ser de dentro. Mas eu ainda me sinto assim na universidade, neste universo que, se é meu, é por insistência minha, porque quase não são os meus que podem estar junto. Então, eu me sinto bem sozinha. Mas aos poucos isso vai ganhando transformações que não podem parar, tal como água de rio, terra de chãos, nuvens do alto bem distante dos homens. É por causa de nossas formas de ocupar este lugar, a universidade (que avançou tão local único, com uma só cor e uma só mentalidade), que ela está bem menos pobre. Mas isso também requer descansos, banhos de rio, porque pisar no terreno minado requer cansativos cuidados. Já desbravar junto, e desmanchar junto, e construir junto, requer um lugar para repousar, se mexer sem se cansar, um solo comum. Eu não consigo descrever tudo o que é comum entre nós. Eu sinto, e isso me basta, porque é imenso.

\begin{tabular}{|l|l|l|l|l|}
\hline Q & Ano 10 & n. 23 & Maio - Agosto 2021 & p. 13 - 32 \\
\hline
\end{tabular}


Vamos aos nossos textos de vida, livros da vida, cursos, estudos. A gente conta uma parte, parte bem importante, mas parte, porque a vida é muito mais e nem tudo se entregará aos registros. E agora já nem se trata só do apolíneo grego, porque já sabemos que o dionisíaco é negro. E as novas formas têm as nossas linhas. Que deixe de ter nossos ressentimentos. Que este lugar seja atravessado logo. Seguimos em composição, Eduardo. São muitas geografias e filosofias para serem instrumentos, em nossas mãos, em nome de novos mapas, novos lugares e nossas vidas.

Um abraço bem longo, que siga no tempo que já tinha começado quando este tempo, que pode ser contado, era tempo menor.

\subsection{Aforismo}

$\S$ Um estilo filosófico em transculturação ${ }^{16}$.

A filosofia clássica nasce com a diversidade de pensamentos, posicionamentos e, com esta diversidade, há também, a diversidade de modos de expressão. Entre os que escreveram, é notória a pluralidade em estilos de escrita. Aforismos, poemas, sentenças, alegorias, ensaios, enigmas, diálogos, monografias, são alguns dos estilos literários que podem ser encontrados no que herdamos deste período frutífero de produção de pensamento. Aristóteles inaugura o estilo lógico-dedutivo de se fazer filosofia. Uma escrita monográfica, caracterizada pela linearidade argumentativa da consequência lógica. A complexidade do estilo aristotélico foi selecionada, na modernidade, como o estilo filosófico por excelência, por refletir a suposta superioridade do pensamento filosófico, em sua pureza, racional, abstrata, em contraposição a escritas artísticas, intuitivas e ilustradas por imagens. A filosofia acadêmica homogeneizou, desta forma, a criação filosófica, determinando seu estilo exclusivo, a dissertação lógico-dedutiva. Existem relevantes e importantes movimentos e pensamentos que questionam a imposição do estilo literário hegemônico como o mais adequado para a exposição do pensamento. Autores que buscaram resgatar a pluralidade de estilos clássicos e resgataram, na modernidade e pós-modernidade, escrituras em aforismos, em sentenças, em romances filosóficos, através de cartas, de ensaios, de peças de teatro, etc. Enquanto latino americanos e brasileiros, somos gerados entre conflituosas relações de transculturação. Além da cultura de matriz europeia, que tenta se impor como hegemônica por inúmeros mecanismos, outras

16 “A noção de transculturação visava a superar a concepção europeia limitada de aculturação e de mestiçagem racial, destacando o movimento contraditório que expressa o encontro de culturas e o processo de 'criação de novos fenômenos culturais"” (HAESBAERT, 2021, p. 77). 
matrizes epistêmicas fortalecem a multiplicidade de linguagens possíveis para a comunicação. A forte corporeidade, oralidade e grafia das matrizes indígenas, africanas e mestiças, devem enriquecer e favorecer o novo em nossas comunicações filosóficas. Podemos ir para além dos pós-modernos, temos insumos para isso. Pensamentos são deslocamentos espaciais, temporais e intelectuais; as dinâmicas territoriais têm consequências epistêmicas.

\subsection{Ensaio: Avaliação, pensamento e aprendizagem}

A oficina ofertada pelo grupo Kalós, sob coordenação das professoras Adriana Delbó e Carmelita Felício, foi terreno fértil para o germinar de pensamentos e reflexões que, se cultivadas com carinho e cuidado, podem tornar-se criações artísticas no estilo filosófico. Fomentar o pensamento crítico, a reflexão, a criatividade, a imaginação, a contemplação e a fruição estética e, a partir desses elementos, materializar as inquietudes em expressões filosóficas é o objetivo de uma atividade denominada oficina, em filosofia, tendo em vista que esse formato de atividades deve ter um caráter prático, e a prática, em se tratando de filosofia, tem a ver com a expressão dos pensamentos, articulados de acordo com a especificidade desse ramo do saber. Para o aprimoramento da prática filosófica é preciso ensaiar, e, nesse processo, a avaliação, seja a efetuada por interlocutores, bem como a autoavaliação, são fundamentais. As notas de rodapé do presente texto são notas de uma releitura autoavaliativa.

A questão da avaliação quanto à produção filosófica é um tema que vai além da relação professor/aluno e da sala de aula. A avaliação diz respeito ao diálogo entre pessoas para aperfeiçoar o hábito cultural de materializar pensamentos e interpretações de mundo em palavras, sejam escritas ou verbalizadas oralmente. A tradição filosófica elegeu esses dois veículos para a comunicação do pensamento. A escrita tem a vantagem de poder ser conservada por mais tempo, deixando disponível para outras gerações o pensamento que foi materializado em um determinado momento. É por isso que Schopenhauer ${ }^{17}$ afirma que aquele que tem algo que acredita ser relevante para a humanidade, procura escrever, pois seria cruel legar seus pensamentos apenas para os da sua geração e da sua localidade, limitando-se a uma transmissão e expressão por via da oralidade. Porém, com o avanço da tecnologia, a linguagem oral também pode ser conservada para a posteridade, e esta oposição escrita/oralidade pode ser que não faça mais tanto sentido.

17 O trecho de Arthur Schopenhauer que aqui faço referência é o seguinte: “... seria uma arrogância espantosa num pensador querer deixar sem uso a mais importante descoberta do gênero humano. Logo, é-me difícil acreditar no espírito verdadeiramente grande daqueles que não escreveram” (SCHOPENHAUER, 2003, p. 32). 
Para além do alcance da linguagem, a defesa da superioridade da escrita em relação à oralidade pode ter um cunho eurocêntrico ${ }^{18}$, pois a escrita foi a maneira que os europeus elegeram para conservar e transmitir seus pensamentos para as gerações futuras. A corporeidade e a oralidade, veículos de expressão potentes para culturas de outras matrizes, como as africanas e indígenas, também foram e são capazes de ser transmitidas de geração à geração e, apesar do epistemicídio praticado pelo imperialismo de origem europeia, que impõe sua auto hierarquização como pensamento superior, dotado de civilização, as culturas de outras matrizes que não tinham a escrita como seu principal veículo, se reproduziram e atravessaram tempo e espaço em condições totalmente adversas.

Um exemplo importante da conservação de uma cultura que transpôs as barreiras do espaço e do tempo, é o da Capoeira Angola, prática que une reflexão intelectual e exercícios físicos, musicalidade, artes plásticas e metafísica. A prática e a reprodução do ritual da Capoeira Angola transmitem e fomentam a criação e recriação de interpretações de mundo a partir da corporeidade. Esta prática, que arrisco denominar como filosófica, sobreviveu ao sequestro de povos africanos, à diáspora forçada e à opressão cultural, e ainda hoje é praticada da maneira como legada pelos africanos, graças à atuação de verdadeiros filósofos, os mestres detentores dos saberes ancestrais, como foi, para citar apenas um deles, aquele que deixou um legado de pensamentos escritos e sistematizado em estilo filosófico, Vicente Ferreira Pastinha ${ }^{19}$.

Sem subverter demasiado o conceito de filosofia, e aceitando sua origem grega e a importância dela na formação da cultura europeia, que foi recriada a partir da arqueologia e difundida por todo o ocidente, através da força do colonialismo, sincretizando-se com culturas de outras matrizes, em uma tensão de transculturação, mas que impõe a suposta superioridade da erudição europeia, me concentrarei aqui, na filosofia em sua forma tradicional.

18 A acusação de eurocentrismo não é justa para com o pensamento de Schopenhauer. Na verdade, este pensador foi um dos principais críticos da suposta superioridade do racionalismo em relação à outras manifestações do pensamento, como as intuições, fonte do conteúdo das obras de arte, esta suposta superioridade é a base para a defesa de que a cultura europeia seria mais civilizada que as outras, por terem sido os criadores das primeiras explicações teóricas para os fenômenos. Schopenhauer foi um dos primeiros filósofos a considerar que o pensamento originário de outras matrizes, como as do oriente, é portador de verdades metafísicas muito mais acertadas que o pensamento lógico dedutivo. E é o que o filósofo assevera quando defende a superioridade da escrita em relação a oralidade: "Os sublimes autores dos Upanixades dos Vedas escreveram, muito embora os Sahita dos Vedas, que consistiam em meras orações, tivessem sido de início propagados apenas oralmente" (SCHOPENHAUER, 2003, p. 32).

19 Dentre os diversos ensinamentos transmitidos por mestre Pastinha, alguns foram por ele escritos e publicados em dois livros, um em vida e outro póstumo. O conteúdo primordial foi transmitido por via da oralidade e corporeidade, mas há trechos dos escritos que expressam a potência da prática da Capoeira Angola, uma filosofia que integraria corpo e mente: “A Capoeira não visa, exclusivamente, preparar o indivíduo para o ataque ou defesa contra uma agressão, mas, desenvolver, ainda, por meio de exercícios físicos e mentais um verdadeiro estado de equilíbrio psico-físico" (PASTINHA, 1988, p. 25).

\begin{tabular}{|c|c|c|c|c|}
\hline Ronista Dialectus & Ano 10 & n. 23 & Maio - Agosto 2021 & p. $13-32$ \\
\hline
\end{tabular}


A filosofia grega, em sua origem, abarcou uma diversidade de modos de comunicação, expressão e linguagem para o pensamento. Os poucos fragmentos conservados demonstram que não havia um estilo de escrita único, pelo contrário, filósofos escreveram poemas, cartas, diálogos, sátiras, aforismos, ensaios, sentenças, peças, tragédias, alegorias e uma infinidade de gêneros literários que nem podemos definir, por não ter sobrevivido ao tempo. Nesse sentido, a escrita não foi assim tão eficaz em ser preservada para as gerações vindouras, e as pinturas rupestres legadas por nossos ancestrais originários dos Cerrados, há onze mil anos atrás, tiveram êxito maior em se perpetuar, ainda que a colonialidade tenha extirpado de nós o saber para interpretá-las. Para além da diversidade em estilos literários, nem todos os filósofos gregos escreveram, e haviam aqueles que preferiam transmitir seus pensamentos a partir da oralidade. Também a corporeidade era uma forma de transmissão de conhecimentos por parte dos gregos antigos, pois é sabido que escolas como a dos pitagóricos, epicuristas e cínicos incluíam dietas como o ascetismo e práticas corporais como inerentes às suas filosofias.

A filosofia como uma prática puramente intelectual é uma invenção da modernidade, assim como a imposição do estilo lógico-dedutivo para sua escrita. Invenções que estão correlacionadas com o projeto de criação dos Estados nacionais e a expansão global do capitalismo, cujo movimento de subjugo de outras culturas através do colonialismo é parcela fundamental.

O desenrolar das reflexões filosóficas ao longo de sua história derrubaram qualquer definição fixa do que seja filosofia, e abriram precedentes para que a dúvida hiperbólica penetrasse em suas próprias entranhas, colocando em xeque as delimitações rígidas entre as áreas do saber, até mesmo em relação aos saberes populares, sem erudição acadêmica. A conceituação da filosofia como racionalismo, universalismo, oposição aos mitos e às paixões, aversão à poesia e às emoções, temas há muito demolidos por pensadores temerários, são claramente carregados de ideologias para conservar um estado artificialmente hierarquizado, de perpetuar opressões, meritocracias e, em escala mundial, de epistemicídios.

A partir dos pressupostos expostos acima, fica difícil delimitar a prática filosófica. Podemos filosofar a partir de qualquer coisa que nos leve a pensar (as oficinas ministradas pela professora Adriana Delbó foram um exemplo disso, de pensamentos filosóficos emergindo das elaborações escritas e faladas dos alunos sobre sua trajetória de serem avaliados pelas instituições escolares), e não há um motivador mais ou menos digno para o pensamento. Podese interpretar a existência e a vida a partir da música, da poesia, da paisagem, da dança, dos

\begin{tabular}{|l|l|l|l|l|}
\hline Q Rovista Dialectus & Ano 10 & n. 23 & Maio - Agosto 2021 & p. 13 - 32 \\
\hline
\end{tabular}


ditos populares, das religiões, da ciência, da sabedoria popular, do cinema, da cultura de massas, etc.

$\mathrm{O}$ ato de interpretar a vida e a existência a partir das mais diversas fontes parece ser uma característica específica da atitude filosófica. A interpretação filosófica precisa ser consistente e argumentativa, as ideias devem ser expostas, sua gênese e relações devem ser explicitadas. Narrar com detalhes e profundidade e horizontalidade os pensamentos que povoam sua mente é o maior desafio do filósofo, é o que distingue um pensamento filosófico de qualquer outro. A argumentação, no sentido de demonstrar que uma visão de mundo é plausível e acrescenta elementos que podem ser compreendidos por qualquer ser humano (mesmo os que não estejam localizados na mesma perspectiva), e suscitar novos pensamentos, é essencial ao filosofar.

Penso que a questão da escrita e da oralidade, mas também a corporeidade, (pois o corpo, os gestos, as expressões, também expressam pensamentos), do exercício de expor pensamentos e organizá-los para que outras pessoas possam compreender e se colocar no lugar de enunciação daquele que expressa, é o principal a ser ensinado a quem se arrisque a aprender a filosofar. No contexto brasileiro, em que a democratização da alfabetização e o hábito da leitura e escrita ainda não são realidade, é fundamental que o ato de escrever seja tratado com atenção redobrada no ensinar a filosofar.

O ensino de filosofia deve passar pelo exame de exposições filosóficas consagradas pela história, mas também pelas esquecidas pelas fontes oficiais, pois são essas leituras que fornecerão o vocabulário específico para que a arte do filosofar se materialize. Deve-se considerar a realidade e as produções de outras linguagens artísticas, aprender a ouvir, a observar e a contemplar, a deixar os pensamentos povoar a mente. Mas deve-se, principalmente, exercitar a escrita, a oralidade e a corporeidade na expressão dos pensamentos.

Minha proposta de avaliação é que se forneça os elementos a partir do qual os neófitos possam refletir, pensar, seja a partir de aulas expositivas, leituras de textos, filosóficos ou não, discussões, momentos contemplativos e que, a partir desse alicerce, o estudante seja incentivado a expressar seus pensamentos, através da escrita, mas também da oralidade e corporeidade, as vezes dando a liberdade para que o estudante escolha o estilo ou gênero da expressão, as vezes direcionando para uma ou outra modalidade. A partir da primeira expressão, o/a avaliador/a vai tecer considerações sobre possíveis deficiências daquela expressão, dificuldades de entendimento, comunicação, etc. para que o estudante possa ensaiar novamente a expressão de suas ideias e, a cada formulação, aperfeiçoe a prática de expressar seus

\begin{tabular}{|l|l|l|l|l|}
\hline Q & Ano 10 & n. 23 & Maio - Agosto 2021 & p. 13 - 32 \\
\hline
\end{tabular}


pensamentos, organize suas ideias de modo que a comunicação atinja o objetivo de apresentar ao interlocutor aquela visão de mundo. A avaliadora/o avaliador, professor/a de filosofia é uma pessoa com experiência na arte de expressar e comunicar pensamentos, e pode diagnosticar fragilidades na exposição ensaiada. Em alguns momentos do processo, a avaliação pode partir de um/a colega que esteja no mesmo caminho de aprendizado, mas, por seu lugar de fala único e diverso, pode ter contribuições interessantes para a lapidação da expressão das ideias.

O processo de avaliação deve girar em torno, portanto, do aperfeiçoamento da expressão das ideias do aprendiz de pensador, e não deve ser um fim para quantificar o nível da expressão, mas um meio para que a/o filósofa/o tenha oportunidade de desabrochar. Os métodos de expressão filosóficos consagrados são modelos importantes para nos inspirarmos, e é fundamental que o estudante tenha acesso à tradição da história da filosofia, para que este conhecimento transpareça no amadurecimento da sua expressão própria.

A apropriação, por parte da professora Adriana Delbó, durante sua exposição nas oficinas, da aproximação que Nietzsche ${ }^{20}$ faz do filosofar com a criação artística (presente também no pensamento de Schopenhauer ${ }^{21}$ ), foi muito feliz. Quando os esboços e rascunhos imperfeitos dos artistas plásticos são examinados ${ }^{22}$, têm-se consciência do longo e trabalhoso processo criativo para gestação de uma obra de arte. O pensamento filosófico passa e deve passar pelo mesmo processo. Um pensamento não surge pronto e acabado como uma iluminação a ser comunicada à humanidade. Ao contrário, ele é resultado de árduo (que pode ser prazeroso) trabalho de forja para que cada detalhe possibilite ao interlocutor fruir a beleza da criação do ser humano em sua máxima potência.

Cartas, apresentações orais, diálogos, escritas em suas mais variadas formas são nossas comunicações a respeito do que nos une - as filosofias, os estudos, a nossa formação, o pensamento que só se dá se permanecer em movimento. A professora, ou o professor, em suas exposições, não ofertam saberes. Ofertam compreensões que já alcançaram. Compreender não é apenas ouvir compreensões. Há algo que desde cedo precisa ser mais comum - as leituras, as

20 Sobre a filosofia como criação artística na obra de Nietzsche: "Na verdade, a fantasia do bom artista ou pensador produz continuamente, sejam coisas boas, medíocres ou ruins, mas seu julgamento, altamente aguçado e exercitado, rejeita, seleciona, combina" (NIETZSCHE apud DELBÓ, 2012, p. 25).

21 Sobre a filosofia como criação artística em Schopenhauer: “... também a filosofia, de acordo com Schopenhauer, é uma repetição de uma intuição contemplativa da essência do mundo (assim como a música também é a repetição sonora não de uma Ideia contemplada, mas da própria Vontade), traduzida para a linguagem abstrata, conceitual, mas por seu fundo intuitivo, na contemplação, a filosofia também é arte, obra do gênio" (FRANCO, 2014, p. 70).

${ }^{22}$ Cadernos de Desenho de Tarsila do Amaral e de Eliseu Visconti organizados por Lygia Eluf, editora da UNICAMP.

\begin{tabular}{|l|l|l|l|l|}
\hline Rovista Dialectus & Ano 10 & n. 23 & Maio - Agosto 2021 & p. $13-32$ \\
\hline
\end{tabular}


escritas, as falas, as tentativas, os ensaios; pensar os pensamentos e não só ouvir alguém expondo seus pensamentos. Os púlpitos e palanques ainda funcionam e deles ainda escorre o sangue dos epistemicídios. A formação da roda ainda está em curso e para tanto nossa geografia é bastante ampla e nossos passos estão se dando. Ocupemos!

\section{REFERÊNCIAS}

DELBÓ, Adriana. Tramas da Filosofia: entre o pensamento e a avaliação. In: FELÍCIO, Carmelita Brito de Freitas (Org.). Filosofia: entre o ensino e a pesquisa. Goiânia: Edições Ricochete, 2012.

DELEUZE, Gilles. Nietzsche e a filosofia. Tradução António M. Magalhães. Porto, Portugal: RÉS Editora, s/d.

DELEUZE, Gilles; GUATTARI, Felix. O que é a filosofia? Tradução Bento Prado Jr. e Alberto Alonso Muñoz. Rio de Janeiro: Ed. 34, 1992.

ELUF, Lygia (org.). Cadernos de desenho Eliseu Visconti. Campinas: Editora da UNICAMP, 2008.

Cadernos de desenho Tarsila do Amaral. Campinas: Editora da UNICAMP, 2008.

FELÍCIO, Carmelita Brito de Freitas. Apresentação. In: FELÍCIO, Carmelita Brito de Freitas (Org.). Filosofia: entre o ensino e a pesquisa. Goiânia: Edições Ricochete, 2012.

FRANCO, Eduardo Ferraz. Schopenhauer, Nietzsche e o livro didático de filosofia. In: FELÍCIO, Carmelita Brito de Freitas (Org.). Filosofia: entre o ensino e a pesquisa. Goiânia: Edições Ricochete, 2012.

FRANCO, Eduardo Ferraz. A unidade metafísica do ser e a relação entre os humanos e os demais animais no pensamento de Schopenhauer. Dissertação de Mestrado. Goiânia: Universidade Federal de Goiás, Faculdade de Filosofia, 2014.

GROSFOGUEL, Ramón. Para descolonizar os estudos de economia política e os estudos póscoloniais: transmodernidade, pensamento de fronteira e colonialidade global. In: SANTOS, Boaventura de Sousa; MENESES, Maria Paula (Orgs.). Epistemologias do Sul. São Paulo: Cortez, 2013.

HAESBAERT, Rogério. Território e decolonialidade: sobre o giro (multi) territorial de(s)colonial na América Latina. Ciudad Autonoma de Buenos Aires: CLACSO; Niterói: Universidade Federal Fluminenese, 2021.

\begin{tabular}{|l|l|l|l|l|}
\hline Q & Ano 10 & n. 23 & Maio - Agosto 2021 & p. 13 - 32 \\
\hline
\end{tabular}


LANDER, Edgardo (org.) A colonialidade do saber: eurocentrismo e ciências sociais. Perspectivas latino-americanas. Ciudad Autonoma de Buenos Aires: CLACSO, 2005.

MARCONDES, Danilo; FRANCO, Irley. A filosofia: O que é? Para que serve? Rio de Janeiro: Zahar, 2011.

MIGNOLO, Walter D. La Idea de América Latina: la herida colonial y la opción decolonial. Barcelona: Editorial Gedisa, 2007.

PASTINHA, Vicente Ferreira. Capoeira Angola. Salvador: Fundação cultural do estado da Bahia, 1988.

PEREIRA, Wigvan. Da bioescrita ao mundo do pensamento. In: FELÍCIO, Carmelita Brito de Freitas (Org.). Filosofia: entre o ensino e a pesquisa. Goiânia: Edições Ricochete, 2012.

SANTOS, Boaventura de Sousa. Para além do pensamento abissal: das linhas globais a uma ecologia de saberes. In: SANTOS, Boaventura de Sousa; MENESES, Maria Paula (Orgs.). Epistemologias do Sul. São Paulo: Cortez, 2013.

SANTOS, Boaventura de Sousa; Meneses, Maria Paula. Prefácio. In: SANTOS, Boaventura de Sousa; MENESES, Maria Paula (Orgs.). Epistemologias do Sul. São Paulo: Cortez, 2013.

SANTOS, Milton. A Natureza do Espaço: Técnica e Tempo, Razão e Emoção. 4. Ed. São Paulo: Editora da Universidade de São Paulo, 2014.

SOUZA, Marcelo Lopes de. Ambientes e Territórios: uma introdução à Ecologia Política. Rio de Janeiro: Bertrand Brasil, 2019.

SCHOPENHAUER, Arthur. El mundo como Voluntad e representación, Tomo II. Tradução: Eduardo Ovejero. In: Obras - La cuádruple raíz del principio de razón suficiente, El mundo como Voluntad e representación e Eudemonologia - Tomo II. Buenos Aires: El Ateneo, 1950.

. Sobre a filosofia universitária. Tradução: Maria Lúcia Cacciola e Márcio Suzuki. São Paulo: Martins Fontes, 2001.

Fragmentos para a história da filosofia. Tradução Maria Lúcia Cacciola. São Paulo: Iluminuras, 2003. 